\title{
BENJAMIN CONSTANT E OS GABINETES DE FÍSICA E QUÍMICA DA ESCOLA NORMAL DA CAPITAL FEDERAL (1890-1892)1
}

\author{
Heloisa Helena Meirelles dos Santos² \\ lattes.cnpq.br/0557807770746922
}

\begin{abstract}
Resumo: O objetivo dessa pesquisa é analisar as razões do envolvimento do Governo Provisório republicano, através do ministro Benjamin Constant Botelho de Magalhães, na montagem dos gabinetes de Física e Química da Escola Normal da Capital Federal. Benjamin Constant enviou à Escola Normal uma série de providências relativas a essa empreitada que compreenderam, dentre outras medidas: fazer seguro do prédio escolar, contratar preparador, adequar instalações de gás e disponibilizar recursos do Tesouro para comprar/transportar os equipamentos em momento crítico de instauração do regime republicano. A pesquisa toma por fontes privilegiadas os documentos do acervo do Centro de Memória do Instituto Superior de Educação do Rio de Janeiro, ainda não tratados historiograficamente, que revelaram a participação de Benjamin Constant e uso da máquina governamental para implantação dos gabinetes; a necessidade da compra do material; as discussões dos professores sobre a falta dos gabinetes e indícios do método utilizado no ensino dos normalistas. A investigação conclui que o pertencimento do Ministro Benjamin Constant ao educandário e a meta governamental de civilizar pela Ciência foram as causas do empenho do governo provisório para montagem dos gabinetes na Escola Normal da Capital Federal.
\end{abstract}

Palavras-chave: História da Educação; Escola Normal da Capital Federal; Implantação dos gabinetes de Física e Química; Benjamin Constant; Cientificismo republicano.

\section{BENJAMIN CONSTANT AND THE OFFICES OF PHYSICS \\ AND CHEMISTRY OF THE NORMAL SCHOOL OF THE FEDERAL CAPITAL (1890-1892)}

\footnotetext{
${ }^{1}$ Versão revisada e ampliada da comunicação individual apresentada no IX Congresso Ibero-americano de História da Educação Latino-Americana (Rio de Janeiro, Brasil, novembro de 2010), sob o título "Pelos vapores do progresso: implantação dos gabinetes de Física e Química na Escola Normal da Capital Federal (1889-1893)". 2 Doutora em Educação pela Universidade do Estado do Rio de Janeiro (Brasil). Contato: helohmei@gmail.com.
} 
Abstract: This research aims to analyze the involvement of the Republican Provisional Government, through minister Benjamin Constant Botelho de Magalhães, in the establishment of the Physics and Chemistry offices of the Normal School of the Federal Capital. Benjamin Constant contributed a series of related measures to the Normal School, which included getting an insurance of the school building, recruiting teachers, adjusting gas facilities, and providing Treasury resources to acquire/transport equipment at a critical moment in the establishment of the Republican regime. The privileged sources of this research include documents from the collection of the Center of Memory of the Higher Institute of Education of Rio de Janeiro, not trated historiographically, which revealed the participation of Benjamin Constant and the use of the governmental structure for the establishment of the offices, the need to purchase material, the teachers' discussions regarding the lack of offices, and indications on the method used in the teaching of normalists. This research shows that Minister Benjamin Constant's membership in the school and the governmental goal of civilizing through science education were the main causes for the commitment of the Provisional Government in establishing the offices in the Normal School of the Federal Capital.

Keywords: History of Education; Normal School of the Federal Capital; Establishment of the Offices of Physics and Chemistry; Benjamin Constant; Republican Scientism.

\section{Escola Normal e professor Benjamin Constant: a relação de sentido}

Este artigo envereda por uma área pouco tratada da história da educação: a razão de certas práticas para o desenvolvimento das disciplinas escolares e, principalmente, o uso do material disponível para que as disciplinas sejam ministradas e aprendidas. Não busco aqui entrar na discussão de Chervel (1990) sobre o estudo histórico das disciplinas, mas interessa-me unir as intenções de ministrá-las, seus usos e suas práticas reais pelo professor. Esta é a razão de ter optado por interpretar os documentos encontrados sobre a instalação dos gabinetes de Física e Química da Escola Normal da Capital Federal, objeto do artigo, a partir da teoria weberiana (1996) como atos de ação humana, que transparecem, simbolicamente, como atos de pertencimento àqueles que se reconhecem 
como iguais. Através desse método dito compreensivo3, busco entender o fato/fenômeno social pelo sentido, porque remonta a outros fatos/fenômenos, acreditando que somente com essa injunção posso compreendê-lo e analisá-lo. Dessa forma, esta narrativa vai percorrer o caminho da intencionalidade individual do sujeito que promove a ação: Benjamin Constant.

Relevante entender que a atuação de Benjamin Constant como diretor da Escola Normal da Corte, e sua atuação de liderança na Congregação, permitiu ao grupo redigir um Regulamento que instituiu um currículo (com escolha de Cadeiras, tempo e método) para a formação de professores primários, o que não existia. Essa intervenção possibilitou que os professores da instituição, naquele momento, criassem uma autoimagem de executores do processo civilizador, em curso no final do Império e início da República, e iniciassem um pertencimento que transpareceu durante a vida de todos. Conta a filha de Benjamin Constant, Bernardina (MAGALHÃES; CASTRO; LEMOS, 2009), em seu diário, que dias antes de se instaurar o governo republicano, Carlos de Laet, monarquista, mas responsável pela redação dos "Sucessos Mais Notáveis do ano letivo de 1880", arranjou emprego para o genro de Benjamin Constant, Dr. Carlos. Em retribuição, Benjamin Constant, ao ver o seu nome na relação de dispensa da Escola Normal, após a derrubada da monarquia, arranjou para que Laet fosse aposentado (jubilado), ao invés de ser demitido. Foi por gratidão ao emprego arranjado pelo amigo ou foi o fato de pertencerem, ambos, a um grupo diferenciado, que Benjamin Constant chefiava, onde se construíram valores, defenderam ideias e partilharam de um mesmo objetivo? Explica Weber (1996, p. 15) que:

No tipo patrimonialista de autoridade, as prerrogativas pessoais do "chefe" são muito mais extensas e parte considerável da estrutura da autoridade tende a se emancipar do controle da tradição. A dominação carismática é um tipo de apelo que se opõe

3 O método compreensivo de Max Weber busca compreender o sentido que as ações de um indivíduo têm e não meramente o aspecto exterior (visível) dessas mesmas ações. "O fato em questão não se esgota em si mesmo e aponta para todo um complexo de significações sociais [...] reconhecidas por uma comunidade maior de pessoas" (TRAGTENBERG, 1997, p. 7). 
às bases de legitimidade da ordem estabelecida e institucionalizada. O líder carismático, em certo sentido, é sempre revolucionário, na medida em que se coloca em oposição consciente a algum aspecto estabelecido da sociedade em que atua. Para que se estabeleça uma autoridade desse tipo, é necessário que o apelo do líder seja considerado legítimo por seus seguidores, os quais estabelecem com ele uma lealdade de tipo pessoal.

A memória biográfica de Benjamin Constant foi explorada por seu principal biógrafo e amigo, Raymundo Teixeira Mendes, inicialmente em 1910, em libreto de 16 páginas, editado pela Igreja Positivista do Brasil4. Esta biografia apresenta Benjamin Constant como um homem culto, carismático, muitas vezes preterido de cargos públicos por força de pouco ou nenhum apadrinhamento, ou por força de sua ideologia, principalmente. Respeitado por alunos e colegas, ainda que estes divergissem de sua identidade política, como é o caso de Carlos de Laet, que embora por convicção um monarquista, o via não como um positivista republicano, mas como primeiro diretor da Escola Normal e presidente de sua Congregação de 1880 a 1885 . Tomando por empréstimo de Mattos (1989) sua análise da implantação da República brasileira, Benjamin Constant pode ser explicado, em outras palavras, pelos nexos pessoais que ele construiu individualmente como professor, principalmente com os alunos e subalternos, já que ele mesmo não vinha da elite ou das "boas famílias”, como se dizia. Explica Castro (2000, p. 6) que a instauração da República foi um golpe militar, mas não de todos os militares, nem de todas as Forças Militares. E, embora existissem republicanos civis, estes estiveram ausentes quando da "conspiração". Poucos eram os oficiais superiores "conspiradores" e o que mais se distinguia não comandava tropas: era o tenente-coronel Benjamin Constant, professor de Matemáticas da Escola Militar.

[As] obras matemáticas de Comte, que se caracterizam pela profundeza metodológica e pela elegante concatenação das matérias, trazendo concepções inteiramente novas sobre a indução e a dedução em matemática, sobre a noção de espaço e sobre a ló-

\footnotetext{
4 Em 1937 houve outra publicação da obra em edição comemorativa do centenário de seu nascimento, publicado pela Imprensa Nacional, com 547 páginas.
} 
gica positiva, exerceram, pela sua clareza e superioridade pedagógica, imensa atração sobre os que se dedicavam, na segunda metade do século XIX, ao ensino e ao estudo da matemática entre nós [...]. (LINS, 1967, p. 54).

No momento em que república era urdida, no final do século XIX, a ciência era a grande novidade, e a revolução tecnológica, oriunda da $2^{\mathrm{a}}$ revolução industrial, iniciava: o emprego do aço, a utilização da energia elétrica e dos combustíveis derivados do petróleo, a invenção do motor a explosão e da locomotiva a vapor e o desenvolvimento de produtos químicos. Por essa razão, pretendia-se que o conteúdo a ser ensinado nas escolas primárias fosse civilizador, "direcionado para a construção da nação, a modernização do país e a moralização do povo" (SOUZA, 2000, p. 9). Ao mesmo tempo, na Escola Normal, o professor Pedro Barreto Galvão, positivista, discutia nas sessões da Congregação, desde 1882, a necessidade de gabinetes próprios pois, mesmo aqueles usados em parceria com a Escola Politécnica, quando a Escola Normal da Corte ocupava o mesmo prédio, não eram próprios e dificultava o entendimento dos futuros professores e a experimentação própria ao ensino nas escolas primárias. No período era grande a difusão do positivismo em várias escolas, dentre as quais a Politécnica5, a Militar, o Liceu de Artes e Ofícios ${ }^{6}$, o Pedro II7 e na Escola Normal.

\footnotetext{
5 Segundo Lins (1967, p. 255-256) destacavam-se como positivistas, dentre outros, os professores: Álvaro de Oliveira, genro de Benjamin Constant, catedrático de Química, foi, em 1878, um dos fundadores da Sociedade Positivista no Rio de Janeiro; Aarão Reis lecionou, na Politécnica, Economia Política; Francisco Behring, que pertenceu ao Apostolado Positivista do Brasil; Francisco Ferreira Braga lente substituto da primeira seção do Curso Geral da Politécnica; Henrique Costa, lecionava Geometria Analítica e era catedrático de Descritiva; Inácio M. Azevedo do Amaral era livre Docente de Geometria Analítica e Cálculo Infinitesimal; João Felipe Pereira; Licínio Athanazio Cardoso e Carlos Sampaio.

${ }^{6}$ No Liceu de Artes e Ofícios lecionaram vários positivistas, destacando-se entre eles o Dr. Francisco Cabrita, Antônio Eugênio dos Santos e Raul Guedes (LINS, 1967, p. 275).

7 No Colégio Pedro II foram professores, entre outros positivistas, o Dr. Antônio Carlos de Oliveira Guimarães, fundador da primeira Sociedade Positivista do Brasil, Timóteo Pereira, Alfredo Coelho Barreto, Rodolfo Paula Lopes, Agliberto Xavier, Pedro do Couto e Hahnemann Guimarães (LINS, 1967, p. 265)
} 
Também repercutiu o Positivismo intensamente na Escola Normal, onde lecionaram, entre outros adeptos das doutrinas de Comte, Benjamin Constant, que foi o seu fundador e primeiro diretor, Agliberto Xavier, Alfredo Soares, Basílio de Magalhães, Francisco Cabrita, Luís Bueno Horta Barbosa, Inácio Azevedo do Amaral, João Soares Rodrigues, Lupércio Hope, Paulo E. de Berredo Carneiro, Pedro Barreto Galvão e Timóteo Pereira. (LINS, 1967, p. 272).

Em 1901, José Veríssimo, professor da Escola Normal, contou que graças principalmente a Benjamin Constant, o positivismo era "quase uma religião do Estado, a qual não era porventura desvantajoso praticar" (LINS, 1967, p. 324). O positivismo, ao determinar os fatos de cada ciência (Física, Química, Matemática, Astronomia, Biologia, Sociologia e Moral), proporcionava conhecimento do mundo e do homem, razão pela qual a doutrina fazia, desde o Império, tanto sucesso entre os intelectuais, dentre os quais os professores. Razão pela qual, para Benjamin Constant, urgia implantar os gabinetes atendendo aos anseios da Escola Normal e também à ideologia que adotara o novo regime.

\section{A instalação começa: chegada dos lotes}

O novo regime ainda lidava com as muitas mudanças estruturais na economia brasileira ${ }^{8}$, como a recentíssima abolição da escravatura, a entrada maciça de imigrantes 9 , o urbanismo acelerado de algumas cidades brasileiras e o desenvolvimento do comércio exterior, quando chegou à Escola Normal ofício para receber, no porto, carga chegada da Europa.

Os embates que, desde a instauração do novo regime, chegavam aos jornais refletiam muitas discussões sobre o papel da República frente ao positivismo, ao país e aos sonhos de cada um daqueles que lutava por

\footnotetext{
8 Para detalhes, ver ABREU, M. P. (org.). A ordem do progresso: dois séculos de política econômica no Brasil. $2^{\text {a }}$ ed. Rio de Janeiro: Campus-Elsevier, 1989.

9 Carvalho (1987, p. 16-17) informa que, em 1890, 28,7\% da população era nascida no exterior e $26 \%$ provinha de outros espaços geográficos brasileiros. No ano seguinte, segundo o autor, cerca de 170 mil imigrantes entraram na cidade do Rio de Janeiro, tendo saído para outros estados cerca de 70 mil.
} 
uma res publica diferenciada. A República visava trazer o público para o movimento político, como desejavam Silva Jardim e Lopes Trovão. E se tentou isso através da criação de jornais e movimentos para trazer ao palco do regime os operários, inspirados pela revolução francesa; mas, também, a República desejava "ter chegado a hora de exercerem a tutela intelectual sobre a nação”, como lembra Carvalho (1987, p. 25). E dentre esses últimos encontrava-se Benjamin Constant.

[...] sob o signo de uma certa pirotecnia de súbitas mudanças que o tempo vivido era percebido na cidade que, na sexta-feira, dia 15 de novembro de 1889 , amanhecera como corte imperial para anoitecer capital republicana. Arrebatado no caudal dos ideais modernos o Rio de Janeiro, no final do século XIX e início do século XX, era palco de não poucas transformações na esfera pública e na vida privada. De olhos postos no outro lado do Atlântico, o Brasil, metonimizado em sua capital, procurava imitar, em faina cega de copistas e fugindo ao transigir mais ligeiro com as exigências da nossa própria nacionalidade [...] os modos de viver, os valores, as instituições, os códigos e as modas daquelas que então eram vistas como as nações progressistas e civilizadas. (NEVES, 2003, p. 18).

O ofício n. 1733, datado de 27 de maio de 1891, informava ao diretor da Escola Normal da Capital Federal sobre o Conhecimento de Embarque $^{10}$ do vapor Parahyba, com a chegada da primeira parte do lote de compras dos experimentos e reativos comprados na Europa para implantação dos Gabinetes de Física e Química do estabelecimento escolar. O documento fora remetido pela Secretaria de Estado dos Negócios da Instrução Pública, Correios e Telégrafos e informava, além embarcação que transportava, o material e a quantidade de barricas e caixas a retirar no porto do Rio de Janeiro, permitindo que pudesse, também, refletir sobre o translado de cargas e pessoas nos vapores nesses anos finais do oitocentos.

No final do século XIX, as viagens para e da Europa se faziam pelos vapores que transportavam em média 1.071 toneladas (LEITE, 1991, p. 742). Essas embarcações, ainda que com os primários recursos tecnológi-

10 Conhecimento de Embarque é um documento emitido pela empresa ou companhia responsável pelo transporte da mercadoria, neste caso, pela Marinha brasileira. 
cos de que dispunham (entre eles a máquina a vapor, a bússola e as cartas náuticas) empreendiam longas viagens entre um e outro continente (ARIAS NETO, 2001) transportando cargas comerciais e pessoas.

Os vapores eram assim chamados porque utilizavam as máquinas a vapor que impulsionavam hélices, fazendo a embarcação se mover. Por isso, foi uma viagem longa para as 19 caixas de equipamentos que a Escola Normal receberia. Nessas embarcações se fazia o transporte de café, maior item da exportação brasileira naquele momento, e se carregava tudo quanto o país importasse nas longas travessias. Era também nesse meio de transporte que chegavam e partiam os viajantes, trazendo ou levando o progresso que a Europa usufruía e o Brasil queria ardentemente copiar nas cargas depositadas em seus porões.

Explica Leite (1991) que os vapores eram mais rápidos que os veleiros que até a pouco tempo eram usados, e previsíveis em sua rota, o que encurtava a viagem. Também, para os passageiros, o navio a vapor era o melhor transporte, pois oferecia camas (em beliches) e roupa de cama, pão fresco todos os dias e área no convés onde eles podiam espairecer e conversar. O preço da passagem, pela segurança e conforto, acrescia de $30 \%$ a 50\% o valor pago por um passageiro de veleiro. Austregésilo (1950), em estudo sobre os meios de transporte brasileiros, comenta que, no início da República, o valor do custo da navegação a vapor da carga era de 12 réis, sendo mensurada por tonelada-quilometro ou em arrobaquilometro.

O vapor Parahyba ${ }^{11}$, que trazia a o primeiro lote da carga para a Escola Normal, era uma embarcação moderna, recentemente construída, mas o acondicionamento da carga era precário, como em todos os navios do mesmo tipo. A Marinha brasileira, desde o término da guerra contra o Paraguai, em 1870, tinha a maior e melhor frota da América do Sul. E esse navio trouxe, sem ônus para o Tesouro, desde Londres, todo o material

${ }^{11}$ O Vapor Mercante Parahyba foi incorporado em 1893, tendo sido o segundo navio a ostentar esse nome na Marinha do Brasil, em homenagem ao estado da Paraíba. Foi considerado como "esquadra rebelde" durante a Revolta da Armada, em 1893, sob o comando do $1^{\circ}$ Tenente Libânio Lamenha Lins de Sousa. Ver: MENDONÇA, M. F.; VASCONCELOS, A. Repositório de Nomes dos Navios da Esquadra Brasileira. $3^{\text {a }}$ edição. Rio de Janeiro: SDGM. 1959, p.197-198. 
comprado pelo Professor Vicente Athanázio Licínio Cardoso ${ }^{12}$, em diferentes cidades europeias, para os Gabinetes de Física e Química da Escola Normal da Capital Federal. Era a forma de também a Marinha estar inserida no projeto civilizatório cientificista empreendido pelo governo republicano, assim como todos os demais setores e órgãos, de forma interligada. Ainda que a Marinha, contraditoriamente, fosse a mais monarquista das Forças Armadas com que contava o país na República.

Ao mandar buscar a carga na Alfândega, o Diretor Francisco Cabritta $^{13}$, provavelmente, comunicou a chegada ao professor engenheiro Pedro Barreto Galvão - que aguardava apreensivo, por certo, desde que elaborou a relação a ser adquirida - e ao preparador João Maria Almeida Nogueira $^{14}$, porque era deles a tarefa de receber, verificar, separar e inventariar o material comprado. Pela quantidade de experimentos, reativos e maquinarias, pouca coisa se quebrou, como demonstra o inventário manuscrito do preparador em livro, então aberto para o registro.

Em junho houve outra remessa a ser transladada do porto. Dessa vez chegaram, de acordo com o Conhecimento de Embarque do vapor Paranaguá, recebido pela Escola Normal15, seis caixas e uma barrica. Novamente, o Diretor comunicou ao professor e ao preparador que logo desempenharam sua tarefa de receber e inventariar também essa carga, bem menor que a anterior. Pouquíssimas perdas ocorreram, como evidencia o documento preenchido por João Maria Nogueira.

Em julho de 1891, outro ofício'16 comunica a chegada da última entrega para a Escola Normal. Desta vez a carga fora transportada pelo vapor Entre Rios: uma caixa de equipamentos. Todos os instrumentos e re-

$12 \mathrm{O}$ professor positivista estava na Europa em viagem pedagógica paga pelo governo republicano e foi designado por Benjamin Constant para comprar, nas lojas indicadas por Pedro Barreto Galvão, os aparelhos, reagentes e peças didáticas que faziam parte da extensa relação encaminhada ao ministro/professor.

13 Segundo Lins (1967), o diretor Francisco Cabritta também era positivista.

$14 \mathrm{O}$ preparador foi contratado no momento em que Benjamin Constant recebeu o pedido dos gabinetes. Enquanto o material era comprado, a Companhia de Gás instalou tubulações no educandário e um seguro do prédio foi feito.

15 O ofício n. 1.798, de 2 de junho de 1891, informa a embarcação, chegada e quantitativo do material transportado.

16 O ofício n. 2.312, de 20 de julho de 1891, especifica o quantitativo de material trazido pelo vapor Entre Rios. 
ativos chegaram de acordo com a lista de compras, sem perdas significativas.

Inventariar todo esse material não foi fácil e o Livro de Inventário demonstra isso. Não só pela grande quantidade de material recebido, mas pelo tempo despendido para realizar a tarefa, que levou pouco mais de um ano. Havia de checar o material na imensa lista de pedidos, definir qual dos Gabinetes - Física ou Química - o receberia, especificá-lo em detalhes, descrever o estado em que chegou, quando ocorreu, além de fazer todas essas anotações no livro manuscrito. Somente no final de 1892 o preparador conseguiu terminar sua tarefa de inventariar.

As primeiras caixas, ao chegarem, revelaram para professores e alunos o que de mais moderno havia em experimentos, maquinarias e reativos para o ensino das cadeiras de Química e Física, então usados na Europa. Chegaram, dentre muitos outros: aparelho para demonstração de compatibilidade e para dilatabilidade dos gases; aparelho de demonstração da Lei de Pascal; Anel de Pacinotti; aparelho de Boyle-Mariotte, entre outros. Estes aparelhos remetiam à ciência da Física, como os reativos representavam as inúmeras combinações e reações químicas. Assim, todo este material significava o progresso visível de que tanto se falava: a cultura materializada em diferentes artefatos científicos de origem europeia. Este fato deve ter sido objeto de comentários de professores e alunos. Todos, possivelmente, se perguntaram como foi que a Escola Normal da Capital Federal conseguiu adquirir toda esses materiais representativos da modernidade.

\section{Um pedido da Escola Normal}

Ao solicitar a Benjamin Constant Botelho de Magalhães auxílio para a implantação dos gabinetes das cadeiras de Física e Química, o Diretor da Escola Normal, Francisco Carlos da Silva Cabritta ${ }^{17}$, pretendia fa-

17 Francisco Carlos da Silva Cabrita (1857-1923) foi secretário da primeira Escola Normal da Corte (criada pelo Decreto no 6370 de 30.11.1876 e a seguir extinta); professor da segunda Escola Normal da Corte (1880-1889) regendo a Cadeira de Geogra- 
zer um pedido ao antigo professor do educandário, seu amigo e seu primeiro Diretor, em benefício dos normalistas e do próprio educandário. Benjamin Constant, professor recém-saído daquelas salas de aula, que passou a integrar o Governo Provisório, ao atender a solicitação do Diretor, levou em conta seu pertencimento àquela escola - certamente, o que dele esperavam os adeptos de uma "república voltada à modernização" (LOPEZ, 1997, p. 14). Não parece ter havido preocupação do professor, como membro de um governo que se instalava, com a depreciação cambial daquele ano de 1891 pelos excessos de papel moeda emitidos nem com a progressiva deterioração das contas externas.

Os anos finais do século XIX foram marcados pela difusão de ideologias cientificistas, especialmente o positivismo, que no Brasil se instalava como ideologia de destaque na República. Os cientificistas brasileiros acreditavam que as ciências experimentais, ou positivas, se constituíam no verdadeiro conhecimento. Este momento era de profundas transformações sociais (fim da guerra contra o Paraguai, abolição da escravatura, instauração da República), o que facilitou a consolidação do ideário positivista de ciência e progresso, que, na fase republicana, incorporou do Império o projeto de construção de uma nação civilizada nos moldes europeus. Aparentemente despreocupado da instauração do plano conservador de saneamento monetário e fiscal, instaurado tão logo o novo regime assume o governo do Brasil, Benjamin Constant atendeu ao oneroso pedido da Escola Normal.

Constituir um governo, consolidar o novo regime e construir a nação eram alguns dos objetivos da República durante o Governo Provisório. Ao instaurar-se, ela já trouxera diferentes concepções ideológicas que, naquele delicado momento, operavam juntas para liderar o país. Problemas existiam em profusão, exigindo que deles dessem conta os lí-

fia. Foi nomeado Diretor da Escola Normal da Capital Federal por Benjamin Constant, ministro da Instrução Pública, Correios e Telégrafos, em 1890. Lecionou no Colégio Pinheiro e na Escola Politécnica. Foi Diretor do Ginásio Nacional. Foi Diretor Geral da Instrução Pública Municipal da cidade do Rio de Janeiro. Colaborou em diversas revistas pedagógicas entre as quais “O Estudo" e "A Escola Primária”, editados por Esther Pedreira de Mello, prefaciou livros e publicou diversos estudos sobre geografia (SANTOS, 2011). 
deres republicanos: desmontar as bases jurídicas monarquistas, convocar a constituinte, organizar o novo governo. Por que razão, com tanto a definir, o Governo Provisório, através de Benjamin Constant, envolveu-se na organização dos gabinetes de Física e Química da Escolar Normal da Capital Federal, senão pelo pertencimento que, como professor da instituição, acreditava ter?

Desde que assumiu o cargo de substituto da cadeira de Física, no final do regime monárquico, o professor Pedro Barreto Galvão ${ }^{18}$ reclamava, durante as sessões da Congregação, presidias por Benjamin Constant Botelho de Magalhães, de acordo com as atas, da falta dos gabinetes para poder lecionar as cadeiras de Química e Física. A mudança de endereço da Escola Normal, das salas da Escola Politécnica para a Praça da Aclamação $\mathrm{n}^{0} 56$, tirou a possibilidade de uso comum dos gabinetes daquela instituição, como havia sido feito desde a criação daquela escola de formação de professores. As aulas ficaram incompreensíveis, o método intuitivo não fazia sentido.

A ida do educandário para a Praça da Aclamação, que permitiu a ocupação de todo um edifício - antes ocupado pela extinta Escola Primária da Freguesia de Sant'Anna - com a possibilidade de uma escola anexa, trouxe o problema da falta de gabinetes. Desse modo, o programa de ensino estabelecido anualmente ficou prejudicado em termos metodológicos porque não havia como usar apenas a palavra para motivar os sentidos, para atingir a racionalidade de que se precisava para aprender estas disciplinas. Sem o uso dos gabinetes e, por consequência, sem a experimentação, como explicar termologia, ótica, barologia, as composições e reações químicas no método intuitivo?

[...] a experimentação é um procedimento aperfeiçoado da observação. O caminho a ser seguido é progredir da percepção à ideia, do concreto ao abstrato, à inteligência por meio dos senti-

18 O professor Pedro Barreto Galvão era engenheiro de formação e o professor responsável pelas cadeiras de Física e Química na Escola Normal da Capital Federal. Antes da República ocupava o cargo de substituto da $4^{\mathrm{a}}$ seção cuja titularidade pertencia, na Escola Normal da Corte, ao Dr. Álvaro Joaquim de Oliveira (Almanak Laemmert, 1889, parte IV, p. 1600). 
dos, ao julgamento por meio de provas [...] (VALDEMARIAN, 2004, p. 107).

O professor Pedro Barreto Galvão, como hábito dos intelectuais ${ }^{19}$ de seu tempo, buscava informar-se das novidades tecnológicas e científicas ocorridas na Europa e publicizadas nas exposições pedagógicas, assim como onde comprar os novos experimentos para uso nas aulas que ministrava. Por essa razão, não foi difícil preparar uma relação de materiais de práticas educativas para que o diretor a encaminhasse ao ministro Benjamin Constant. A relação continha inúmeros experimentos, reativos e maquinarias necessárias às lições, bem como também indicava, na Europa, as empresas vendedoras.

A historiografia tem mostrado que a circulação de modelos pedagógicos pela intelectualidade se fez através de discursos, livros e materiais, dentro e fora das fronteiras nacionais (MIGNOT; GONDRA, 2007). Por isso, as exposições pedagógicas, dentre elas as Paris (1867), Viena (1873), Rio de Janeiro (1883) e Londres (1884), foram relevantes a muitos professores-viajantes não só pela observação de vários objetos para a prática educativa, mas pela leitura de manuais e folhetos distribuídos nas exposições de que faziam parte. Destas exposições também participavam as fábricas industriais, dentre elas aquelas que produziam materiais educativos. O conhecimento adquirido por quem participava das exposições não era só para ele próprio, ou para o seu círculo profissional. Gondra (2007, p. 67) cita também os "livros de viajantes", comuns no século XIX, que eram publicados e que levavam a diferentes públicos os estudos que a viagem proporcionara.

Ao receber a longa lista elaborada cuidadosamente pelo professor Galvão, composta não só de experimentos recém-fabricados, como também de reativos que possibilitavam reproduzir vários fenômenos, o ministro Benjamin Constant designou o professor e lente da Escola Militar

\footnotetext{
19 A palavra intelectual foi aqui tomada no sentido de Bobbio (1997, p. 68): "um intelectual é alguém que não faz coisas, mas reflete sobre as coisas, que não maneja objetos, mas símbolos, alguém cujos instrumentos de trabalho não são máquinas, mas ideias".
} 
Vicente Athanazio Licínio Cardoso ${ }^{20}$ para comprar o material solicitado. Ele já se encontrava em viagem à Europa para ver e compreender o cotidiano e as soluções pedagógicas do estrangeiro.

Em prosseguimento aos seus atos para implantar os gabinetes de Física e Química da Escola Normal, o ministro Benjamin Constant disponibilizou oito contos de réis da conta de "Eventuaes do Tesouro Nacional”, em Londres, pelo Ofício ${ }^{0}{ }^{1.463}$, de 25 de setembro de 1890, para que se efetivassem as compras. Naquele momento o Governo Provisório ainda se inteirava das contas do Tesouro, como de tantas outras informações financeiras, administrativas e estratégicas, mas, de todo o modo, a quantia em Londres foi reservada para este fim.

Neste período desenvolvia-se no Brasil a política do encilhamento, comandada pelo jurista Rui Barbosa, que consistia em ampliar a circulação monetária através da emissão de dinheiro, no intuito de modernizar a nação pelo incremento de créditos maiores para o setor industrial. Por isso, e pela especulação que tal política causou na Bolsa de Valores, e por consequência em todo o país, dispor de oito contos de réis para a instalação de gabinetes na Escola Normal era um indício de que a Escola Normal estava inserida numa proposta prioritária do movimento republicano que se iniciava.

O Ministério da Instrução Pública, Correios e Telégrafos fez, a seguir, um seguro do prédio da Escola Normal no valor de um conto de réis. Este seguro mostrou a preocupação do Governo com o próprio municipal $^{21}$ em vista das novas atividades de experimentações físicoquímicas com uso de reativos e de gás, de consequências aparentemente desconhecidas, feitas por alunos nos gabinetes que estavam sendo implantados. Também mandou instalar no educandário, conforme a carta de 26 de agosto de 1891, da Diretoria da Companhia Nacional de Ar Comprimido ao Diretor da Escola Normal, aparelhos da Companhia

${ }^{20}$ O Ofício $\mathrm{n}^{0} 1.463$, de 25 de setembro de 1890, do Ministério dos Negócios da Instrução Pública, Correios e Telégrafos, informa ao Diretor da Escola Normal a designação do professor Vicente Athanazio.

${ }^{21}$ Próprio municipal é uma terminologia burocrática, muito usada nos séculos XIX e $\mathrm{XX}$, que explica que uma dada construção pertence à municipalidade, o que dá a este poder de propriedade. 
Economizadora de Gaz do Rio de Janeiro, o que poderia ser de utilidade nos gabinetes. Para dar visibilidade à modernidade que se imprimia à Escola Normal, mandou também instalar um relógio movido a ar comprimido no frontispício do prédio, grande novidade europeia.

Além disso, o ministro Benjamin Constant nomeou João Maria Almeida Nogueira, indicado pelo professor Pedro Barreto Galvão, como preparador dos gabinetes de Física e Química da Escola Normal, com as atribuições de inventariar e preparar o material que ainda estava sendo comprado na Europa, e somente chegaria ao Brasil no ano seguinte.

\section{Medidas póstumas}

[...] facilitem o desempenho da comissão incumbida pelo Governo dos Estados Unidos da América do Norte [representada] pelo Capitão Alexandre Rodgers e Lientenant Frank E. Sassyer [...] encarregados dos trabalhos relativos à Exposição Columbiana em Chicago conhecida pela denominação "The World's Columbian Exposition”22.

Este foi o texto do ofício encaminhado à Escola Normal, logo depois da morte de Benjamin Constant, pela Secretaria de Estado dos Negócios da Instrução Pública, Correios e Telégrafos. Enquanto a instituição ainda pranteava seu ex-diretor, a Secretaria da Instrução Pública, Correios e Telégrafos já alertava a necessidade de uma boa acolhida aos preparadores da Exposição de Chicago, realizada em 1893, da qual o Brasil participaria.

Era importante para a jovem república brasileira consolidar-se como regime e, ao mesmo tempo, visibilizar as realizações e sonhos de progresso. Assim, foram gastos cerca de 600 mil dólares na construção do pavilhão brasileiro, considerado um dos mais majestosos das delegações estrangeiras durante a Exposição Colombiana (VIRMOND et al., 2008, p. 141). Era uma forma bem dispendiosa de apresentar a pujança republicana num momento em que os gêneros alimentícios aumentavam, as em-

22 Ofício Circular n. 1.409, de 4 de maio de 1891, da Secretaria de Estado dos Negócios da Instrução Pública, Correios e Telégrafos ao Diretor da Escola Normal. 
presas fechavam suas portas e o povo começara a desconfiar que a república não era tudo aquilo com que sonhara.

Neste momento confuso e turbulento, o governo montava na Escola Normal os gabinetes de Física e Química. Esta condição modelar que era associada à Escola Normal da Capital Federal legitimou-se quando Benjamin Constant, então ministro da Instrução Pública, Correios e Telégrafos, encaminhou a diferentes países e estados brasileiros, o Regulamento da Escola Normal23, de 1890, tendo por espelho o regulamento que os professores daquele educandário haviam escrito à luz de suas experiências no cotidiano escolar, em 1881.

A condição modelar da Escola Normal republicana deu a instituição uma efetiva participação no projeto de construção e civilização da nação que estava sendo desenvolvido pelo Governo. Interessava, então, investir nesta escola de formação de professores para atingir o desenvolvimento científico no país.

O desenvolvimento científico, no pensamento positivista, facilitaria o desenvolvimento da indústria. Era importante e imprescindível, no entanto, que o povo se "civilizasse" de modo a que o país progredisse. Trazer civilização era, naquele momento, educar o povo, dando-lhes instrução, normas de conduta, lições de higiene e qualquer outro tipo de co-

23 Benjamin Constant envia o Regulamento da Escola Normal a países e unidades da federação como modelo de formação de professores. Vide: Centro de Memória do Instituto Superior de Educação do Rio de Janeiro. Correspondências 1890-1891: Carta de 11 de julho de 1890 (do Consulado Geral dos Estados Unidos do Brazil, em Montevidéo); Ofício s/n de 25 de junho de 1890 (do Palácio do Governo do Estado do Maranhão); Ofício $\mathrm{n}^{\circ} 135$ de 23 de junho de 1890 (do Estado Federado do Sergipe, Palácio do Governo em Aracaju); Ofício 2929 de 20 de junho de 1890 (do Estado do Ceará, Casa do Governo); Ofício de 19 de junho de 1890 (do Palácio do Governo do Estado de Alagoas); Ofício s/n de 18 de junho de 1890 (do Estado Federal de Santa Catarina, Palácio do Governo); Carta de 18 de agosto de 1890 (do Consulado Geral do Brazil, em Buenos Aires); Ofício ${ }^{0} 720$ de 22 de agosto de 1890 (Secretaria de Governo do Estado do Piauhy); Carta de 28 de agosto de 1890 (do Consulado Geral do Brazil, em Paris); Carta de 29 de agosto de 1890 (do Consulado Geral dos Estados Unidos do Brazil, em Antuérpia); Ofício n ${ }^{0} 133$ de 30 de agosto de 1890 (do Consulado Geral do Brazil na Itália, Genova); Carta de 9 de setembro de 1890 (do Consulado Geral do Brazil, em Genebra); Carta de 1 de outubro de 1890 (do Consulado Geral do Brazil no Chile, Valparaíso); carta de 14 de fevereiro de 1891 (do Consulado Geral do Brazil nos Estados Unidos, New York) e Ofício n ${ }^{0}$ 102, de 22 de abril de 1891 (da Diretoria do Pedagogium). 
nhecimento que tornasse homogênea a população em termos civilizatórios. E, para isso, as escolas serviam como um poderoso instrumento que, não só instruíam, mas homogeneizavam valores e disciplinavam. As Escolas Normais e, dentre elas, aquela legitimada como modelar, formariam os professores que deveriam "civilizar" o povo.

Por conta do projeto de construção de uma nação civilizada, moderna e industrial, com os mesmos costumes, língua, e ocupando um território que fora consolidado no Império, o Governo Provisório voltou-se para concluir, postumamente, o trabalho de Benjamin Constant na implantação dos gabinetes de Física e Química da Escola Normal, através do transporte do material comprado na Europa pelo professor Athanazio e transladado pelos vapores da Marinha brasileira.

\section{Conclusão}

O investimento do governo republicano na implantação dos Gabinetes de Física e Química da Escola Normal da Capital Federal, e isso inclui não só o material comprado, mas também as mudanças implementadas no prédio escolar, mostra-se como uma face da política positivista do Governo Provisório voltada para a educação. A educação era o elemento primordial na criação de uma nação "civilizada" a partir da instrução do povo, pelos professores, nas escolas públicas primárias. Atender a esta perspectiva do Governo Provisório tendo como modelo a formação de professores da Escola Normal da Capital Federal foi viável na medida em que este educandário já tinha sido legitimado desde o Império. Além disso, o educandário estava situado na capital do país, o que dava visibilidade às ações ali realizadas. A Escola Normal sempre teve o quadro de professores formado por intelectuais das mais diferentes procedências (SANTOS, 2011).

Os materiais comprados em empresas europeias especializadas representam os avanços científicos e tecnológicos da revolução industrial. Difundiam-se no Brasil através de livros, jornais, impressos, viagens de estudos, como a que fazia o professor Athanázio, e Exposições internaci- 
onais. Não deveriam ser somente conhecidos, como partilhados por professores e pelas pessoas comuns, através dos livros publicados sobre os estudos de viagem. O interesse do governo brasileiro nas exposições internacionais mostra que a República desejava tornar visível o progresso que o Brasil estava conquistando a partir do regime recém-instaurado, o que era uma estratégia de consolidá-lo.

O papel de Benjamin Constant Botelho de Magalhães na implantação dos Gabinetes de Física e Química foi decisivo para beneficiar a instituição em que trabalhava e da qual fora o primeiro diretor, o que mostra um pertencimento seu àquele grupo, mas que atendeu também, naquele momento, de forma bem pragmática, ao projeto de nação que, como partícipe do Governo Provisório republicano, ele também desejava implementar: o cientificismo positivista.

Em suma, este texto mostra como o governo republicano, ainda em seu período provisório, imprimiu a partir de uma instituição de cunho modelar para a formação de professores primários, a Escola Normal da Capital Federal, uma perspectiva científica. A ciência deveria ser ensinada aos futuros professores primários de modo que o repassassem a seus futuros alunos. E isso somente foi possível a partir da implantação e uso dos gabinetes de Física e Química da Escola Normal da Capital Federal, por Benjamin Constant, que associou esta ação ao ideal positivista de progresso para a construção de uma nação civilizada.

\section{Referências}

ARIAS NETO, J. M. Em busca da cidadania: praças da Armada Nacional (1867-1910). Tese (Doutorado em História). Universidade de São Paulo, São Paulo, 2001.

AUSTREGÉSILO, M. E. Estudo sobre alguns tipos de transporte no Brasil colonial. Revista de História, p. 495-516, 1950.

BOBBIO, N. Os intelectuais e o poder: dúvidas e opções dos homens de cultura na sociedade contemporânea. São Paulo: UNESP, 1997. 
CARVALHO, J. M. Cidadania no Brasil: o longo caminho. $3^{\mathrm{a}}$ ed. Rio de Janeiro: Civilização Brasileira, 2002.

. A construção da ordem. Teatro de sombras. $3^{\mathrm{a}}$ ed. Rio de Janeiro: Civilização Brasileira, 2007

- Os bestializados: o Rio de Janeiro e a república que não foi. São Paulo: Companhia das Letras, 1987

CASTRO, C. A proclamação da República. Rio de Janeiro: Jorge Zahar, 2000.

CHERVEL, A. História das disciplinas escolares: reflexões sobre um campo de pesquisa. Teoria \& Educação, n. 2, Porto Alegre, p. 177-229, 1990.

GONDRA, J. G. Exercício de comparação: um normalista da Corte na Europa. In: MIGNOT, A. C. V.; GONDRA, J. G. (org.). Viagens pedagógicas. São Paulo: Cortez, 2007.

LEITE, J. C. O transporte de emigrantes: da vela ao vapor na rota do Brasil, 1851-1914. Análise Social, v. 26, n. 112/113, p. 741-752, 1991.

LEMOS, R. L. C. Benjamin Constant: biografia e explicação histórica. Estudos Históricos, n. 19, p. 67-81, 1997.

LINS, I. História do positivismo no Brasil. São Paulo: Companhia Editora Nacional, 1967.

LOPEZ, L. R. Uma história do Brasil: República. São Paulo: Contexto, 1997.

MAGALHÃES, B. B.; CASTRO, C.; LEMOS, R. O diário de Bernardina: da monarquia à república, pela filha de Benjamin Constant. Rio de Janeiro: Zahar, 2009.

MATTOS, I. R. Do Império à República. Estudos Históricos, n. 4, p. 163$171,1989$.

MIGNOT, A. C. V.; GONDRA, J. G. Viagens de educadores e circulação de modelos pedagógicos. In: Viagens pedagógicas. São Paulo: Cortez, 2007.

NEVES, M. S. Os cenários da República. O Brasil na virada do século XIX para o século XX. In: DELGADO, L. A. N.; FERREIRA, J. L. Brasil Republicano: Estado, sociedade civil e cultura política. Rio de Janeiro: Civilização Brasileira. 2003, p. 14-44.

SANTOS, H. H. M. Congregação da Escola Normal: da legitimidade outorgada à legitimidade (re) conquistada (1880-1910). Dissertação (Mestrado em Educação), Universidade do Estado do Rio de Janeiro, Rio de Janeiro, 2011.

SILVEIRA, A. B. História do Instituto de Educação. Rio de Janeiro: Prefeitura do Distrito Federal, 1954. 
SOUZA, R. F. Inovação educacional no século XIX: a construção do currículo da escola primária no Brasil. Cadernos Cedes, ano XX, n. 51, 2000, p. 9-28.

TRAGTENBERG, M. Apresentação. In: WEBER, Max. Textos selecionados. São Paulo: Nova Cultural, 1997.

VALDEMARIAN, V. T. O método intuitivo: os sentidos como janelas e portas que se abrem para um mundo interpretado. In: SAVIANI, D. et al. (org.). O legado educacional do século XIX. Campinas: Autores Associados, 2006.

VIRMOND, M. C. L. et al. Carlos Gomes e a Exposição Colombiana Universal. Anais do XVIII Congresso da Associação Nacional de Pesquisa e Pós-Graduação. Salvador: ANPPOM, 2008.

WEBER, M. A ética protestante e o espírito do capitalismo. $11^{\mathrm{a}}$ ed. São Paulo: Pioneira, 1996.

. Textos selecionados. São Paulo: Nova Cultural, 1997.

\section{Fontes}

Brazilian Government Document Digitization. Relatório do Ministério dos Negócios do Império apresentado em 1885. Anexo D. Exposições e Congressos. Ministerial Reports (1821-1960).

. Almanak Administrativo, Mercantil e Industrial do Império do Brazil para $1889.46^{\circ}$ ano.

Centro de Memória do Instituto Superior de Educação do Rio de Janeiro. Livro de Correspondências, 1890-1891.

. Livro de Inventário dos Gabinetes de Física e Química, 18901894.

. Atas da Congregação, 1880-1890.

. Livro de Ofícios, 1888-1890.

Recebido em 04 de janeiro de 2017. Aprovado em 22 de fevereiro de 2017. 